\title{
Clinical effectiveness of a manual based coping strategy programme (START, STrAtegies for RelaTives) in promoting the mental health of carers of family members with dementia: pragmatic randomised controlled trial
}

\author{
(c) (1) () OPEN ACCESS
}

Gill Livingston professor of older people's mental health ${ }^{1}$, Julie Barber lecturer in medical statistics ${ }^{2}$, Penny Rapaport principal clinical psychologist ${ }^{3}$, Martin Knapp professor of social policy ${ }^{4}$, Mark Griffin lecturer in medical statistics ${ }^{2}$, Derek King research fellow ${ }^{5}$, Debbie Livingston trial manager ${ }^{1}$, Cath Mummery consultant neurologist, honorary senior lecturer ${ }^{6}$, Zuzana Walker reader in psychiatry of the elderly ${ }^{1}$, Juanita Hoe senior clinical research associate ${ }^{1}$, Elizabeth L Sampson clinical senior lecturer ${ }^{1}$, Claudia Cooper clinical senior lecturer ${ }^{1}$

${ }^{1}$ Mental Health Science, University College London, London W1W 7EJ, UK ; ${ }^{2}$ Statistical Science and PRIMENT clinical trials unit, University College London, Gower Street, London, UK; ${ }^{3} \mathrm{Camden}$ and Islington NHS Foundation Trust, London, UK; ${ }^{4}$ Personal Social Services Research Unit, London School of Economics and Political Science, London, UK; ${ }^{5}$ Institute of Psychiatry, King's College London, UK; ${ }^{6}$ Dementia Research Unit, University College London

\begin{abstract}
Objective To assess whether a manual based coping strategy compared with treatment as usual reduces depression and anxiety symptoms in carers of family members with dementia.

Design Randomised, parallel group, superiority trial.

Setting Three mental health community services and one neurological outpatient dementia service in London and Essex, UK.

Participants 260 carers of family members with dementia.

Intervention A manual based coping intervention comprising eight sessions and delivered by supervised psychology graduates to carers of family members with dementia. The programme consisted of psychoeducation about dementia, carers' stress, and where to get emotional support; understanding behaviours of the family member being cared for, and behavioural management techniques; changing unhelpful thoughts; promoting acceptance; assertive communication; relaxation; planning for the future; increasing pleasant activities; and maintaining skills learnt. Carers practised these techniques at home, using the manual and relaxation $\mathrm{CDs}$.
\end{abstract}

Main outcome measures Affective symptoms (hospital anxiety and depression total score) at four and eight months. Secondary outcomes were depression and anxiety caseness on the hospital anxiety and depression scale; quality of life of both the carer (health status questionnaire, mental health) and the recipient of care (quality of life-Alzheimer's disease); and potentially abusive behaviour by the carer towards the recipient of care (modified conflict tactics scale).

Results 260 carers were recruited; 173 were randomised to the intervention and 87 to treatment as usual. Mean total scores on the hospital anxiety and depression scale were lower in the intervention group than in the treatment as usual group over the eight month evaluation period: adjusted difference in means -1.80 points $(95 \%$ confidence interval -3.29 to $-0.31 ; \mathrm{P}=0.02$ ) and absolute difference in means -2.0 points. Carers in the intervention group were less likely to have case level depression (odds ratio $0.24,95 \%$ confidence interval 0.07 to 0.76 ) and there was a non-significant trend towards reduced case level anxiety $(0.30,0.08$ to 1.05$)$. Carers' quality of life was higher in the intervention group (difference in means $4.09,95 \%$ confidence interval 0.34 to 7.83 ) but not for the recipient of care (difference in means $0.59,-0.72$ to 1.89$)$. Carers in the intervention group reported less 
abusive behaviour towards the recipient of care compared with those in the treatment as usual group (odds ratio $0.47,95 \%$ confidence interval 0.18 to 1.23 ), although this was not significant.

Conclusions A manual based coping strategy was effective in reducing affective symptoms and case level depression in carers of family members with dementia. The carers' quality of life also improved.

Trial registration Current Controlled Trials ISCTRN70017938.

\section{Introduction}

The number of people living with dementia is rising rapidly owing to increased longevity. Dementia not only affects the person with the condition but also family members and society, through increasing dependence and challenging behaviour. ${ }^{1}$ In the United Kingdom, dementia care is estimated to cost $£ 23 \mathrm{bn}$ per year, and this is projected to treble in the next 30 years as the number of older people increases. ${ }^{2}$ Families and individuals bear the biggest burden; two thirds of people with dementia live at home and receive most of their care from family members, who therefore save the economy a considerable amount of money. ${ }^{2}$ About $40 \%$ of carers of family members with dementia have clinically significant depression or anxiety, and others have significant psychological symptoms. ${ }^{34}$ These symptoms are more common when the family carer is older, a woman, living with the recipient of care, reports a greater carer burden, and the care recipient has more neuropsychiatric symptoms, although they seem unrelated to the severity of the dementia. ${ }^{34}$ The psychological morbidity of carers predicts a breakdown in care and therefore the need for placement in a care home ${ }^{5}$ as well as elder abuse. ${ }^{6}$ Thus improving the psychological health of the carers may not only improve their quality of life but also that of the recipient of their care. In the long term the need for placement in a care home may be delayed and thus bring economic benefits.

Although UK policy recognises that psychological therapy for carers of family members with dementia should be a key component of high quality dementia care, in practice resources are not available, and this is partly because so far effective therapies have been delivered only by highly trained clinical psychologists and evidence on cost effectiveness is lacking. ${ }^{7}$ The national agenda in the United Kingdom is to have a stepped care approach to improve access to psychological therapies, where less intensive therapy is delivered ${ }^{8}$ by graduates supervised by clinical psychologists. A befriending programme delivered by former carers was ineffective in reducing the carers' anxiety or depression. ${ }^{9}$ The Coping with Caregiving programme was developed in the United States. ${ }^{10}{ }^{11}$ This manual based group intervention comprising 12 sessions delivered by clinical psychologists has been shown to reduce depression. ${ }^{12} 13$ Therapies individualised to carers seem to be most effective in delaying admission of the recipients of care to a care facility and are more effective than group interventions in reducing morbidity in carers. ${ }^{12}{ }^{14}$ Interventions that require active participation of caregivers have the greatest effect. ${ }^{15}$

We carried out a randomised controlled trial in the United Kingdom to test a manual based therapy for carers of family members with dementia and to test the effectiveness of using psychology graduates without clinical qualifications to deliver therapy to this group.

\section{Methods}

The supplementary file provides the full protocol of this pragmatic multicentre randomised controlled trial. Our intervention, based on the US Coping with Caregiving programme, was individual and manualised and required active participation. Our primary objective was to determine the clinical effectiveness (measured by the hospital anxiety and depression scale) and cost effectiveness (reported in an accompanying paper ${ }^{16}$ ) of eight sessions of a manual based coping strategy, delivered over 8-14 weeks by supervised psychology graduates to carers of family members with dementia, compared with usual service provision, over eight months.

The secondary outcomes were depression and anxiety caseness on the hospital anxiety and depression scale; quality of life of both the carer and the recipient of the care; and abusive behaviour by the carer. We plan on analysing time to entry to 24 hour care of the family member with dementia at longer term follow-up (at two and seven years).

\section{Recruitment and follow-up}

We recruited carers to the trial from 4 November 2009 to 8 June 2011. The first four month follow-up took place on 4 March 2010, with the final eight month follow-up on 7 February 2012.

\section{Setting}

We recruited through disparate settings: two mental health trusts' memory services (Camden and Islington Foundation Trust, urban setting; North Essex Partnership Foundation Trust, suburban and rural); the North East London Foundation Trust Admiral nurse, suburban (specialist nurses for carers of family members with dementia); and the Dementia Research Centre-National Hospital for Neurology and Neurosurgery, a tertiary service with a high rate of referrals for young people with early onset dementia.

\section{Participants}

We included carers of family members referred in the previous year who provided emotional or practical support at least weekly and identified themselves as the primary carer of a family member with dementia not living in 24 hour care. We excluded carers who were unable to give informed consent to the trial, were currently taking part in a randomised controlled trial in their capacity as a carer, or who lived more than 1.5 hours travelling time from the researchers' base. We administered the mini-mental state examination ${ }^{17}$ to carers aged 60 or over only at baseline. If they scored less than 24 the research assistant discussed the participant with GL or CC to see whether this was related to cognition, mood, or education. If carers were judged to have a dementia they were not included in the study and we informed the referring clinician.

\section{Procedure}

Prospective participants were initially approached by a clinician and given or sent an information sheet. Those interested in participating were referred to the research team. The referral gave the name, sex, and relationship to the family member of the prospective participant as well as the patient's sex. The researchers telephoned the carer 24 hours or more after they received the information sheet. The researchers answered any questions and then arranged to meet those who agreed to take part to obtain their informed consent and complete baseline assessment before randomisation.

\section{Allocation to trial groups}

To conceal allocation we used an online computer generated randomisation system to allocate participants to the intervention or to treatment as usual. This system was set up and maintained 
by an independent clinical trials unit and accessed by the START trial manager. Randomisation was stratified by trust using random permuted blocks. To allow for potential clustering effects in the intervention arm we used an allocation ratio of 2:1 (intervention: treatment as usual). ${ }^{18}$ A member of the therapy team then phoned the participants and informed them of their allocation, either to treatment as usual when they would be contacted for a four month follow-up or to the intervention when an appointment was made for the therapy to start. Allocation within the individual teams was according to workload.

\section{Assessments}

Carers were interviewed at baseline and at four and eight months after randomisation, usually in their own home, unless they preferred to come to the research team base in University College London. We have continued to follow up carers, asking them to remain in the study for two years even if the recipient of their care had been placed in a care home or died. Results of this longer term follow-up will be reported separately.

Information collected at baseline consisted of sociodemographic details about the carer and recipient of the care; and clinical and resource use items (as detailed in the accompanying paper). At both the four and eight month follow-up we repeated the collection of clinical and resource use information.

Sociodemographic details obtained at baseline included age, sex, ethnicity, relationship to the recipient of care (for example, spouse, child), level of education, last occupation, and living situation.

Measures regarding the carer's health and wellbeing collected at all three study time points were:

- The hospital anxiety and depression scale, ${ }^{19}$ a self completed scale, which has been validated for all age groups and settings, in people who are physically well or unwell, and in Asian and African ethnic groups. ${ }^{20}$ The scale determines caseness of depression and anxiety with scores ranging from 0 to 21 and as a total score ranging from 0 to 42 (higher scores indicating more symptoms). We chose the total score as our primary outcome because it has a better sensitivity and positive predictive value than either of the individual scales in identifying depression when compared with the international classification of diseases criteria. ${ }^{21}$ The anxiety and depression score was also dichotomised as "case" and "non-case," with a cut-off point of $8 / 9 .^{20}$

- The Zarit burden interview, a 22 item self report questionnaire, is the most consistently used measure of burden in carers ${ }^{22}$; scores range from 0 to 88 , with higher scores indicating more burden.

- The modified conflict tactics scale is a self completed measure of potentially abusive behaviour by carers towards the recipient of their care. ${ }^{23}$ Ten behaviours are scored as to whether, during the previous three months, these have occurred never (0), almost never (1), sometimes (2), most of the time (3), or all of the time (4), and these items can be added to make a score. These behaviours range from shouting to threatening to shaking or slapping. A score of 2 or more on any one of the items is classified as an abusive behaviour. If participants scored this on any item, we discussed the score with a supervising clinician and if it was judged that the recipient of care was at risk, permission was asked to inform the clinical team so that the carer and recipient of care could have appropriate help.

- Health status questionnaire, ${ }^{24} 25$ mental health domain, measures health related quality of life throughout the age ranges and is sensitive to change. It is summarised as a continuous score, ranging from 0 to 100 , with higher scores indicating better outcome.

- The brief COPE, a self completed measure of coping strategies by the carer, validated in carers of family members with dementia, with subscales that measure problem focused, emotion focused, and dysfunctional coping. ${ }^{26} 27$

At all time points, we also asked carers for information about the recipient of their care:

- The neuropsychiatric inventory ${ }^{28}$ is a validated instrument with 12 symptom domains that are scored for their severity and frequency and summarised as a single continuous score (higher scores indicating worse symptoms). We included this tool as neuropsychiatric symptoms have been shown to be associated with psychological morbidity of carers.

- The clinical dementia rating, which we used as an informant instrument, grades the level of impairment of someone with dementia (categories: healthy, very mild, mild, moderate, severe). ${ }^{29}$

- Quality of life-Alzheimer's disease ${ }^{30}$ was rated by the carers, to assess the family member's overall quality of life. The total score ranges from 13 to 52, with higher scores indicating better outcome.

\section{Blinding}

We blinded outcome assessors to randomisation status, but it was not possible to blind the study participants. The researchers worked in two teams, each assessing outcomes for approximately half the participants and providing therapy to those allocated to treatment in the half of participants they were not assessing. Assessors asked participants at the beginning of each interview not to disclose their allocation group.

\section{Therapy intervention}

With the first author's permission, we developed an individual therapy programme (START, STrAtegies for RelaTives) based on the Coping with Caregiving programme from the United States. We adapted it for UK use for individual carers of family members with dementia over eight sessions (box). The therapy took place where the carers preferred, usually in their homes, without the family member with dementia in the room. The therapy was carried out with an interpreter if the carer did not speak English fluently.

\section{Training and delivery}

We employed and trained psychology graduates with no clinical training to deliver the intervention. The training programme had a strong practical focus on how to deliver the therapy, potential clinical dilemmas, working with interpreters, empathic listening skills, effective use of supervision, and when to ask for help. We trained the therapists to adhere to the manual and required them to demonstrate, by role play, competence in delivering each session of the intervention. Our clinical psychologist (PR) met with each team of therapists for 1.5 hours of group clinical supervision every fortnight. She also had one hour of dedicated time per week for individual consultation as needed by the therapists. The therapists recorded one therapy session per participant, selected at random, and a researcher not involved in the therapy used a standard checklist to rate the session for fidelity to the manual. Overall fidelity scores ranged from 1 to 5 , with 5 being high. If fidelity scores were not high 


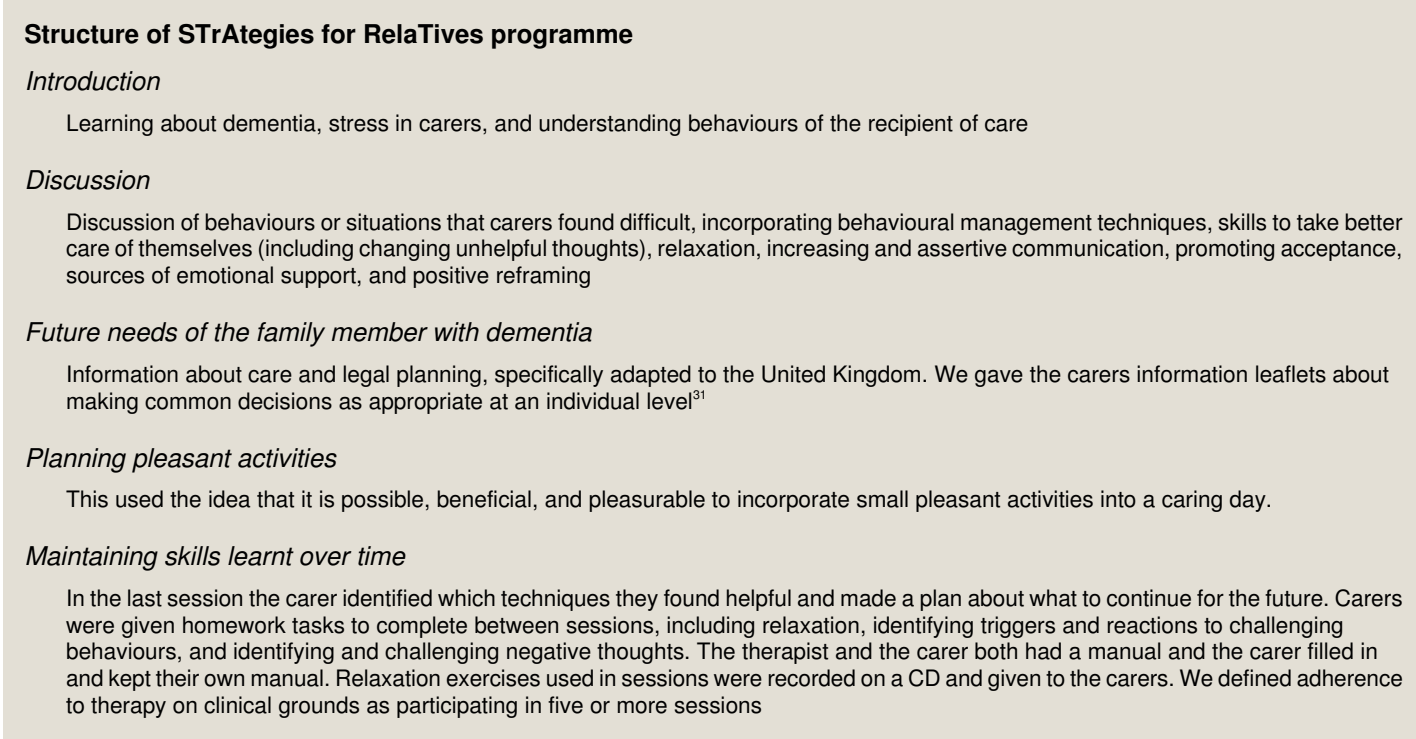

the supervising clinical psychologist discussed this in supervision.

\section{Treatment as usual}

In the treatment as usual group, services were based around the family member with dementia. Standard treatment concerns medical, psychological, and social issues. Thus the treatment consisted of assessment, diagnosis, and information; drug treatment; cognitive stimulation therapy; practical support; treatment of neuropsychiatric and cognitive symptoms; and carer support. In each setting, treatments aimed to be in line with the clinical guidelines for good dementia care of the National Institute for Health and Care Excellence. ${ }^{32}$

\section{Power calculation}

This study was originally powered for a primary outcome of anxiety score on the hospital anxiety and depression scale based on data from a cross sectional pilot study of carers of family members with dementia. Mean anxiety scores for this group were 7.2 (SD 4) points. We considered a decrease of 2 points in mean score and 0.5 change in standard deviation to be clinically significant (expert consensus). To detect such a difference with $90 \%$ power at a $5 \%$ significance level, we required 75 participants in each group. To account for therapist clustering, we used a design effect of 1.87 for the intervention group, assuming an average of 30 carers per therapist and an intracluster correlation of $0.03 .{ }^{33}$ Based on these calculations and inflating for $20 \%$ attrition, we planned to recruit 90 participants in the treatment as usual group (no clustering) and 168 participants in the intervention group (clustering).

After recruitment, the research team (with approval from the funding body while the database was still locked) agreed that the primary outcome should be changed to the total score on the hospital anxiety and depression scale as this has been shown to have better sensitivity and positive predictive value than either of the individual anxiety and depression scores in identifying depression. We calculated that the sample size then available (87 treatment as usual, 173 intervention group) would be sufficient to detect a mean difference in total score on the hospital anxiety and depression scale of at least 2.4 points (with $80 \%$ power, $5 \%$ significance), which was considered to be clinically important. This calculation assumed a standard deviation for the total score of 7.4 (as seen in pilot data), allowed for analysis of covariance (with assumed correlation 0.5), and repeated follow-up measurements at four and eight months (assumed correlation 0.7). We factored in drop-out rates at $10 \%$ (based on that observed), and we applied a revised design effect of 1.4 for the intervention arm (using an intracluster correlation of $0.03^{34}$ and the observed average cluster size of 15 carers for each therapist).

\section{Statistical analysis}

In the primary analysis we used regression methods to estimate group differences in total score on the hospital anxiety and depression scale over the eight month follow-up. We used random effects models to account for the therapist clustering in the intervention arm and repeated measurements at four and eight months. We adjusted for baseline total score and centre (on which randomisation was stratified) and also on factors believed to affect affective symptoms (carer's age, sex, carer burden, and neuropsychiatric symptoms of the recipient of the care). We carried out all analyses by intention to treat but excluded carers with data missing at both the four and the eight month follow-up.

We used sensitivity analyses to reanalyse the primary outcome and to assess robustness of our conclusions. Analyses considered adjustment for imbalances in baseline characteristics between the randomised groups and the differential effects of treatment over time (treatment by time interaction). Using logistic regression we also investigated the extent to which missing outcomes varied by baseline characteristics; we then repeated the main analyses adjusting for those factors associated with missingness.

We applied similar approaches for analysis of the secondary outcomes. For binary outcomes we used random effects logistic regression. We compared entry of the family member with dementia to 24 hour care between groups using a simple comparison of proportions (not allowing for clustering) because of small numbers.

All statistical analyses followed a predefined analysis plan and were carried out using STATA version 11.

\section{Results}

The figure $\Downarrow$ shows the recruitment and flow of participants in the trial. Of the 450 carers eligible for the study, 260 (58\%) consented to take part in the trial; the remained refused to participate or were not contactable. The numbers recruited from 
individual trusts were: Camden and Islington Foundation Trust $\mathrm{n}=183$, North East London Foundation Trust $\mathrm{n}=16$, Dementia Research Centre $n=35$, and North Essex Partnership Foundation Trust $n=26$. Table $1 \Downarrow$ compares the known personal details of those who consented and those who did not and shows that the study sample had good external validity. Those who consented were, however, slightly more likely to be married or partnered with the recipient of care than those who did not consent.

Overall, 173 (67\%) participants were randomised to the intervention group and 87 to treatment as usual. In general, the randomised groups were well balanced for patient and baseline carer personal and clinical characteristics (tables $2 \Downarrow$ and $3 \Downarrow$ ). Employment status, however, appeared imbalanced, with a higher proportion of retired carers in the intervention group. Carers in the intervention group were also slightly older and included a higher proportion of those currently unmarried. Higher proportions of carers in the intervention group were living with the recipient of care, were spouses or partners, and with either no school level qualifications or tertiary education. In terms of clinical characteristics those in the intervention group less frequently had case level anxiety and had slightly lower anxiety scores and total scores on the hospital anxiety and depression scale.

The 10 therapists (seven women) in the intervention arm each saw between 11 and 32 participants. All the therapists were psychology graduates with no further clinical training and aged 20-35 years.

\section{Treatment fidelity and participant follow-up}

Over the eight months after baseline, 10 carers from the control group and 21 from the intervention group were withdrawn or lost to follow-up (figure). These included two who died (one from each group). In the intervention group one carer gave inconsistent data and was withdrawn by the team, and one was in prison. The participants gave several reasons for withdrawal: wanted treatment but not allocated to it (four, treatment as usual), did not feel the intervention was for them (three, intervention), too busy (four, intervention; one, treatment as usual), disliked talking about the recipient of care without him or her present (one, treatment as usual; one, intervention), other family member wanted them to withdraw (one, treatment as usual), unwell (one, intervention), recipient of care died (one, treatment as usual), and trial too upsetting (one, intervention). Six gave no reason (five, intervention; one, treatment as usual). Three others did not participate and were not contactable at the four or eight month follow-up, but have since come back to the study.

Overall, 128 participants in the intervention group agreed to a therapy session being audio-recorded to assess fidelity to the manual (from 1 for poor to 5 for excellent); 100 (78\%) rated fidelity as 5, $20(16 \%)$ as 4 , five as 3, and three as 2 .

Of the eight therapy sessions offered, five or more were attended by $130(75 \%)$ carers in the intervention group (table $4 \Downarrow$ ). Eight $(5 \%)$ of those in the intervention group withdrew before taking part in any therapy sessions. Adherence (attending $\geq 5$ sessions) was better in those of white ethnicity compared with other ethnicity $(\mathrm{n}=110(78 \%) v \mathrm{n}=19(61 \%))$ and slightly better for male compared with female carers $(46(81 \%) v 84(72 \%))$ and those with at least A level education $(56(80 \%) v 74(72 \%))$. Adherence was similar by age group $(<60,75(77 \%) v 55(73 \%))$ and employment status (in paid work $49(78 \%) v$ other 81 $(74 \%)$ ).

\section{Primary and secondary clinical outcome results}

Table $5 \Downarrow$ summarises average scores at months 4 and 8 , and gives the estimated effect of therapy versus treatment as usual for primary and secondary outcomes.

Analysis of the total score on the hospital anxiety and depression scale, adjusting for centre and baseline score and for factors related to outcome (carers' age and sex, neuropsychiatric inventory score, and Zarit burden interview score) showed a mean difference of -1.80 points ( $95 \%$ confidence interval -3.29 to -0.31 points; $\mathrm{P}=0.02$ ) in favour of the intervention. If the model did not include factors relating to outcome then the results were similar, with an average decrease in score of $-1.46(-2.89$ to -0.03$) ; \mathrm{P}=0.05$ ). The therapist intracluster correlation at four months was 0.02 (95\% confidence interval 0.00 to 0.09 ) and at eight months was 0.00 (0.00 to 0.08$)$. Sensitivity analyses adjusting for significant personal and clinical predictors of missing values - namely, recipient of care living with carer, relationship to carer, carer having dependent children at home, ethnicity of recipient of care, and COPE dysfunction score-gave similar results (mean difference $-1.53,95 \%$ confidence interval -2.96 to -0.10 ) as did analyses adjusting for baseline imbalances-namely, carer's work situation, relationship to carer and recipient of care, and carer's education and living situation (mean difference $-1.78,-3.30$ to -0.27 ). Models including an interaction with time showed no evidence of a differential effect of the intervention between the four and eight month time points $(\mathrm{P}=0.90)$. Models for the individual anxiety and depression continuous scales also showed evidence of beneficial effects of the intervention (table 5).

\section{Secondary outcomes}

Depression and anxiety caseness - a reduction in the odds of cases of depression on the hospital anxiety and depression scale in the intervention group compared with treatment as usual was significant, with an odds four times higher for the treatment as usual group (odds ratio $0.24,95 \%$ confidence interval 0.07 to $0.76)$. Similarly there was some evidence for a reduction in odds of caseness on the hospital anxiety and depression scale $(0.30$, 0.08 to 1.05$)$.

Significant abuse - there was some evidence of a decrease in abusive behaviour on the modified conflict tactics scale (odds ratio $0.48,0.18$ to 1.27 ).

Quality of life of carer and recipient of care-There was no significant difference between the groups for overall quality of life for the family members with dementia. The health status questionnaire, mental health scale for the carer did, however, indicate significantly higher average scores and hence improved mental health (mean difference $4.09,95 \%$ confidence interval 0.34 to 7.83 ).

\section{Entry of family members with dementia to 24 hour care}

Fourteen family members with dementia were admitted to a care home during the eight month follow-up period; three (4\%) in the treatment as usual group and $11(6 \%)$ in the intervention group. Simple analyses indicate no evidence of a statistically significant difference between the groups (Fishers exact test $\mathrm{P}=0.56$ ). This outcome will be considered more extensively in analyses of longer term follow-up. Cost effective results are reported in the accompanying paper. 


\section{Discussion}

Carers of family members with dementia referred to secondary or tertiary care benefit from a structured psychological intervention delivered by psychology graduates, supervised by clinical psychologists. The effect size in terms of the total mean affective symptoms was small, but previous evidence where researchers set out to calculate what a clinically important difference would be on the hospital anxiety and depression scale, suggests that treatment effects are in the range that is important to patients. ${ }^{35}$ Incidence of clinical depression increased in the treatment as usual group but not in the intervention group and the odds ratios indicate that at follow-up, those in the treatment as usual group were four times more likely to have clinically significant depression, suggesting the intervention is clinically important. In keeping with this, the quality of life improved for carers. We thought that in the long term this intervention may also delay admission to care homes for people with dementia and therefore increase their quality of life. This short term follow-up over eight months did not show that but we plan to continue collecting data at two years and for care home admission over the following five years, and we will reconsider this effect.

\section{Strengths and limitations of this study}

This was a pragmatic study with broad inclusion criteria, including participants from a range of settings and backgrounds, with varied personal characteristics, suggesting the results are generalisable and directly relevant to the National Health Service. Further evidence of external validity is the similarity in characteristics between those who did and did not consent. The intervention is standardised, and the high fidelity ratings and the low intracluster correlations within therapists suggested that the intervention can be delivered consistently. The follow-up rate of $88.1 \%$ overall was satisfactory, with similar rates in both arms. The instruments were validated and standardised.

The levels of anxiety and depressive symptoms, case level anxiety and depression, neuropsychiatric symptoms, and carer abusive behaviour were slightly higher than in a recent cohort study of newly referred people with dementia, so those with more problems may have been more likely to consent to the study. ${ }^{636}$ We informed the clinical teams about abusive behaviour of the carers in the treatment as usual group when there was not an intervention in place and thus may have improved the outcome for that group. Although randomisation was independent and follow-up raters were blinded to allocation, the carers inevitably knew to which group they had been randomised. We found it difficult to deliver the therapy to people who did not speak English, although only four such carers were in the study, three of whom were in the intervention group. In retrospect, we did not allow enough time and budget to translate the whole manual and deliver the therapy with translators. As translating the manual is a one-off process, this will be less of a problem as we come to implement our findings in the NHS.

\section{Comparisons with other studies and meaning and implications of this study}

Other recent psychosocial interventions have been, in contrast, ineffective for both carer psychological symptoms and quality of life; thus showing our findings were not explained by the offer of a therapist to spend time and attention. ${ }^{97}$ Our study is consistent with the US study from which we derived the intervention, in that a similar intervention helped depressive symptoms in carers, but it was more practical for many carers as we did not require them all to come to a group session at the same time. It was deliverable by psychology graduates without previous clinical training - a group who are relatively inexpensive and available. Within the United States, a similar therapy to ours delivered at an individual level was found to be significantly cost effective in completers compared with controls for freeing up time spent on care. ${ }^{38} \mathrm{We}$ are not aware of any other interventions in this group for which health economic evaluations have been undertaken and this is in our accompanying paper. In our earlier studies we found that family carers tended to become more anxious and depressed over time without intervention, and that this was associated with an increase in abusive behaviour, and thus we included carers who were not depressed at presentation to services. ${ }^{39}{ }^{40}$ The preventive effect that was found highlights that these carers can benefit from early intervention.

The intervention was effective in the short term and acceptable to most participants, who made time for it despite their care commitments, and often also being employed or unwell themselves. We found little evidence of harm with withdrawal from the treatment, being at a similar rate to withdrawal from the treatment as usual arm, although one carer said they found the therapy too upsetting and three thought it was not for them. We think memory services should consider offering the intervention as part of the routine management of dementia, and it is being piloted by our local services. Our group has developed the training and the manual is available (see supplementary file).

Currently, no interventions have been shown to reduce the abuse of elders. ${ }^{41}$ Our study was not powered to find a significant change in abuse, and for ethical reasons we made clinicians aware of abuse in the control group; thus carers were often offered clinical and social support.

\section{Unanswered questions and future research}

This study reports short term outcomes for carers and that there was no evidence of a difference between groups at four and eight months, thus possibly suggesting some lasting effect. In one study, continued therapy led to improvement in carers' mental health over years and a reduction in nursing home admissions for patients, but we do not yet know whether our short therapeutic intervention to change strategies will also be effective in the longer term. ${ }^{42}$

We are following this cohort to answer these questions. In addition, the effect on abuse is promising but more work is required for confirmation of this effect. The longer term outcome may help to clarify this situation.

\section{Conclusions}

The intervention was clinically effective for the impact on carers in the short term. Further follow-up will consider longer term effects on carers' mood, quality of life, and abusive behaviour, and on cost effectiveness, and whether, as in other longer term studies, patients' time to care home admission has been lengthened. ${ }^{43}$

We thank Dolores Gallagher Thompson for her original manual and allowing us to change it; the participating carers; the Camden and Islington NHS Foundation Trust, University College London Hospital, the North East London Foundation Trust, and the North Essex Partnership Foundation; Vincent Kirchner and Lisa Gee for referring many patients; members of the steering committee: Joanna Murray (chair), Thana Balamurali, Kate Maxmin, Lynne Ramsay, Mabel Saili, and Lynis Lewis; and the data monitoring committee: Cornelius Katona (chair) and U Hla Htay. The Start research team acknowledges the 


\section{What is already known on this topic}

About $40 \%$ of carers of family members with dementia have clinically significant depression or anxiety, and others have significant psychological symptoms

A manual based group intervention delivered by clinical psychologists in the United States has been shown to reduce depression

Effective therapies have so far only been delivered by highly trained clinical psychologists

\section{What this study adds}

A manual based coping strategy programme can be delivered by graduate psychologists without clinical training

The intervention was effective in reducing affective symptoms and case level depression of carers of family members with dementia

support of the National Institute for Health Research, through the Dementia and Neurodegenerative Research Network (DeNDRoN)

Contributors: GL, CC, JH, ZW, DL, SN, CM, MK, ELS, and PR contributed to the conception and design of the study. GL, CC, JH, ZW, $\mathrm{JB}$, and $M G$ contributed to the analytic plan. JB and $M G$ analysed the clinical data. GL, CC, ZW, JH, and $\mathrm{CM}$ led recruitment from their trusts. GL drafted the article and JB, PR, MK, MG, DK, DL, CM, ZW, JH, ELS, and $C C$ revised it critically for important intellectual content and gave final approval of the version to be published. The researchers/therapists Monica Manela, Ryan Li, Elanor Lewis-Holmes, Ruth Shanley, Amy Waugh, Lynsey Kelly, Allana Austin, Peter Keohane, Shilpa Bavishi, Amanda Shulman, and Jonathan Bradley collected and entered the data and implemented the manual. Shirley Nurock gave advice throughout as an expert family carer. GL will act as guarantor Funding: This project was funded by the National Institute for Health Research Health Technology Assessment (HTA) programme (project No 08/14/06) and will be published in full in Health Technology Assessment. Further information on the project is available at www. nets.nihr.ac.uk/projects/hta/081406. The authors analysed results and prepared this manuscript independently of the funding body. The views and opinions expressed therein are those of the authors and do not necessarily reflect those of the HTA programme, National Institute for Health Research, National Health Service, or the Department of Health. The study was sponsored by University College London. Neither funders nor sponsors had a role in the study design and the collection, analysis, and interpretation of data and the writing of the article and the decision to submit it for publication. The researchers were independent from funders and sponsors. All researchers could access all the data.

Competing interests: All authors have completed the ICMJE uniform disclosure form at www.icmje.org/coi_disclosure.pdf (available on request from the corresponding author) and declare: support from Health Technology Assessment for the submitted work; no financial relationships with any organisations that might have an interest in the submitted work in the previous three years; no other relationships or activities that could appear to have influenced the submitted work.

Ethical approval: The trial was conducted in accordance with Good Clinical Practice guidelines, the Declaration of Helsinki, the Clinical Trials Regulations and local laws and regulations. We obtained written ethics approval for the study from East London and the City Research Ethics Committee 1 for the trial (ID: 09/H0703/84) and Research and Development permission from the local trusts. All participants gave written informed consent.

Data sharing: No additional data available.

Transparency: The lead author affirms that this manuscript is an honest, accurate, and transparent account of the study being reported; that no important aspects of the study have been omitted; and that any discrepancies from the study as planned (and, if relevant, registered) have been explained. The lead author in this statement is the study guarantor.

Ferri CP, Prince M, Brayne C, Brodaty H, Fratiglioni L, Ganguli M, et al. Global prevalence of dementia: a Delphi consensus study. Lancet 2005;366:2112-7.

2 Knapp M, Prince M, Albanese E, Banerjee S, Dhanasiri S, Fernandez J, et al. Dementia UK (a report to the Alzheimer's Society on the prevalence and economic cost of dementia in the UK produced by King's College London and London School of Economics). Alzheimer's Society, 2007

3 Cooper C, Balamurali TB, Livingston G. A systematic review of the prevalence and covariates of anxiety in caregivers of people with dementia. Int Psychoger 2007;19:175-95.

4 Mahoney R, Regan C, Katona C, Livingston G. Anxiety and depression in family caregivers of people with Alzheimer disease: the LASER-AD study. Am J Geriat Psychiatry 2005; 13:795-801

5 Brodaty $\mathrm{H}$, Gresham M. Effect of a training programme to reduce stress in carers of patients with dementia. BMJ 1989;299:1375-9.

6 Cooper C, Selwood A, Blanchard M, Walker Z, Blizard R, Livingston G. The determinants of family carers' abusive behaviour to people with dementia: results of the CARD study. $J$ Affect Disord 2010;121:136-42.

7 Knapp M, Lemmi V, Romeo R. Dementia care costs and outcomes: a systematic review. Int J Geriatr Psychiatry 2013;28:551-61.

8 The depression report a new deal for depression and anxiety disorders. The Centre for Economic Performance's Mental Health Policy Group, 2006.

9 Charlesworth G, Shepstone L, Wilson E, Reynolds S, Mugford M, Price D, et al. Befriending carers of people with dementia: randomised controlled trial. BMJ 2007;336:1295-7.

10 Coon DW, Thompson L, Steffen A, Sorocco K, Gallagher-Thompson D. Anger and depression management: psychoeducational skill training interventions for women caregivers of a relative with dementia. Gerontologist 2003:43:678-89.

11 Gallagher-Thompson D, Solano N, McGee JS, Krisztal E, Kaye J, Coon DW, et al. Coping with caregiving: reducing stress and improving your quality of life. Stanford University School of Medicine and VA Palo Alto Healthcare System, 2002.

12 Selwood A, Johnston K, Katona C, Lyketsos C, Livingston G. Systematic review of the effect of psychological interventions on family caregivers of people with dementia. $J$ Affect Disord 2007:101:75-89.

13 Cooper C, Balamurali TBS, Selwood A, Livingston G. A systematic review of intervention studies about anxiety in caregivers of people with dementia. Int $J$ Ger Psychiatry 2007;22:181-8.

14 Spijker A, Vernooij-Dassen M, Vasse E, Adang E, Wollersheim H, Grol R, et al. Effectiveness of nonpharmacological interventions in delaying the institutionalization of patients with dementia: a meta-analysis J Am Geriatrics Soc 2008:56:1116-28.

15 Pinquart M, Sorensen S. Helping caregivers of persons with dementia: which interventions work and how large are their effects? Int Psychogeriatr 2006;18:577-95.

16 Knapp M, King D, Romeo R, Schehl B, Barber J, Griffin M, et al. Cost effectiveness of a manual based coping strategy programme in promoting the mental health of family carers of people with dementia (the START (STrAtegies for RelaTives) study): a pragmatic randomised controlled trial. BMJ 2013;347:f6342.

17 Folstein MF, Folstein SE, Mchugh PR. Mini-Mental State - practical method for grading cognitive state of patients for clinician. J Psychiatric Res 1975;12:189-98.

18 Roberts C, Roberts SA. Design and analysis of clinical trials with clustering effects due to treatment. Clin Trials 2005;2:152-62.

19 Zigmond AS, Snaith RP. The hospital anxiety and depression scale. Acta Psychiatr Scand 1983;67:361-70.

20 Bjelland I, Dahl AA, Haug TT, Neckelmann D. The validity of the Hospital Anxiety and Depression Scale. An updated literature review. J Psychosom Res 2002;52:69-77.

21 Spinhoven P, Ormel J, Sloekers PPA, Kempen GIJM, Speckens AEM, VanHemert AM. A validation study of the Hospital Anxiety and Depression Scale (HADS) in different groups of Dutch subjects. Psychol Med 1997;27:363-70.

22 Zarit SH, Reever KE, Bach-Peterson J. Relatives of the impaired elderly: correlates of feelings of burden. Gerontologist 1980;20:649-55.

23 Beach SR, Schulz R, Williamson GM, Miller LS, Weiner MF, Lance CE. Risk factors for potentially harmful informal caregiver behavior. J Am Geriatr Soc 2005;53:255-61.

24 Barry TL, Kaiser KL, Atwood JR. Reliability, validity, and scoring of the Health Status Questionnaire-12 version 2.0. J Nurs Meas 2007;15:24-35.

25 Pettit T, Livingston G, Manela M, Kitchen G, Katona C, Bowling A. Validation and normative data of health status measures in older people: the Islington study. Int $J$ Geriatr Psychiatry 2001;16:1061-70.

26 Carver CS. You want to measure coping but your protocol's too long: consider the brief COPE. Int J Behav Med 1997;4:92-100.

27 Cooper C, Katona C, Livingston G. Validity and reliability of the brief COPE in carers of people with dementia: the LASER-AD Study. J Nerv Ment Dis 2008:196:838-43.

28 Cummings JL, Mega M, Gray K, Rosenberg-Thompson S, Carusi DA, Gornbein J. The Neuropsychiatric Inventory: comprehensive assessment of psychopathology in dementia. Neurology 1994;44:2308-14.

29 Hughes CP, Berg L, Danziger WL, Coben LA, Martin RL. A new clinical-scale for the staging of dementia. Br J Psychiatry 1982;140:566-72.

30 Logsdon RG, Gibbons LE, McCurry SM, Teri L. Assessing quality of life in older adults with cognitive impairment. Psychosom Med 2002;64:510-9.

31 Livingston G, Leavey G, Manela M, Livingston D, Rait G, Sampson E, et al. Making decisions for people with dementia who lack capacity: qualitative study of family carers in UK. BMJ 2010;341:c4184.

32 National Institute for Health and Care Excellence. Dementia guideline CG42. NICE, 2006

33 Walwyn R, Roberts C. Therapist variation within randomised trials of psychotherapy: implications for precision, internal and external validity. Stat Methods Med Res 2010;19:291-315. 
34 Fossey J, Ballard C, Juszczak E, James I, Aldler N, Jacoby R, et al. Effect of enhanced psychosocial care on antipsychotic use in nurshig home residents with severe dementia: cluster randomised trial. BMJ 2006;332:756-8A.

35 Puhan MA, Frey M, Buchi S, Schunemann HJ. The minimal important difference of the hospital anxiety and depression scale in patients with chronic obstructive pulmonary disease. Health Qual Life Outcomes 2008;46:doi:10.1186/1477-7525-6-46

36 Cooper C, Selwood A, Blanchard M, Walker Z, Blizard R, Livingston G. Abuse of people with dementia by family carers: representative cross sectional survey. BMJ 2009;338:b155.

37 Waldorff FB, Buss DV, Eckermann A, Rasmussen ML, Keiding N, Rishoj S, et al. Efficacy of psychosocial intervention in patients with mild Alzheimer's disease: the multicentre, rater blinded, randomised Danish Alzheimer Intervention Study (DAISY). BMJ 2012;345:e4693.

38 Nichols LO, Chang C, Lummus A, Burns R, Martindale-Adams J, Graney MJ, et al. The cost-effectiveness of a behavior intervention with caregivers of patients with Alzheimer's disease. J Am Geriatr Soc 2008;56:413-20.

39 Cooper C, Katona C, Orrell M, Livingston G. Coping strategies, anxiety and depression in caregivers of people with Alzheimer's disease. Int J Geriatr Psychiatry 2008;23:929-36.

40 Cooper C, Blanchard M, Selwood A, Walker Z, Livingston G. Family carers' distress and abusive behaviour: Iongitudinal study. Br J Psychiatry 2010;196:480-5.
41 Cooper C, Selwood A, Livingston G. Knowledge, detection, and reporting of abuse by health and social care professionals: a systematic review. Am J Geriatr Psychiatry 2009;17:826-38.

42 Mittelman MS, Haley WE, Clay OJ, Roth DL. Improving caregiver well-being delays nursing home placement of patients with Alzheimer disease. Neurology 2006;14:1592-9.

43 Andren S, Elmstahl S. Effective psychosocial intervention for family caregivers lengthens time elapsed before nursing home placement of individuals with dementia: a five-year follow-up study. Int Psychogeriatrics 2008;20:1177-92.

Accepted: 30 September 2013

\section{Cite this as: BMJ 2013;347:f6276}

This is an Open Access article distributed in accordance with the Creative Commons Attribution Non Commercial (CC BY-NC 3.0) license, which permits others to distribute, remix, adapt, build upon this work non-commercially, and license their derivative works on different terms, provided the original work is properly cited and the use is non-commercial. See: http://creativecommons.org/licenses/by-nc/3.0/. 


\section{Tables}

Table 1| External validity of eligible carers who consented to the trial compared with those who were not randomised

$$
\text { No (\%) of eligible carers }
$$

Characteristics Not randomised $(n=190)$ Randomised $(n=260)$

\section{Male carers} $56(29)$ $82(32)$

Male recipients of care

75 (39) $108(42)$

Carers relationship to recipient of care:

\begin{tabular}{lcc}
\hline Spouse or partner & $65(34)$ & $109(42)$ \\
\hline Child & $90(47)$ & $113(44)$ \\
\hline Friend & $8(4)$ & $6(2)$ \\
\hline Daughter's or son's partner & $4(2)$ & $12(5)$ \\
\hline Nephew or niece & $8(4)$ & $8(3)$ \\
\hline Grandchild & $4(2)$ & $6(2)$ \\
\hline Sibling & $5(3)$ & $4(2)$ \\
\hline Other & $6(3)$ & $2(1)$
\end{tabular}


Table 2| Baseline personal characteristics of carers and family members with dementia by randomisation group. Values are numbers (percentages) unless stated otherwise

\begin{tabular}{|c|c|c|c|c|}
\hline \multirow[b]{2}{*}{ Characteristics } & \multicolumn{2}{|c|}{ Carers } & \multicolumn{2}{|c|}{ Recipients of care } \\
\hline & $\begin{array}{l}\text { Treatment as usual group } \\
\qquad(\mathrm{n}=87)\end{array}$ & Intervention group ( $n=173)$ & $\begin{array}{l}\text { Treatment as usual group } \\
\qquad(\mathrm{n}=87)\end{array}$ & Intervention group $(n=173)$ \\
\hline Mean (SD) age (years) (range) & $56.1(12.3)(27-89)$ & $62.0(14.6)(18-88)$ & $78.0(9.9)(53-96)$ & $79.9(8.3)(55-95)$ \\
\hline Women & $62(71)$ & $116(67)$ & $50(57)$ & $102(59)$ \\
\hline Men & $25(29)$ & $57(33)$ & $37(43)$ & $71(41)$ \\
\hline Ethnicity: & & $\mathrm{n}=172$ & & \\
\hline White UK & $65(75)$ & $131(76)$ & $61(70)$ & $126(73)$ \\
\hline White other & $5(6)$ & $10(6)$ & $6(7)$ & $14(8)$ \\
\hline Black and in minority ethnic group & $17(20)$ & $31(18)$ & $20(23)$ & $33(19)$ \\
\hline \multicolumn{5}{|l|}{ Marital status: } \\
\hline Not currently married & $25(29)$ & $61(35)$ & $47(54)$ & $92(53)$ \\
\hline Married or cohabiting & $62(71)$ & $112(65)$ & $40(46)$ & $81(47)$ \\
\hline \multicolumn{5}{|l|}{ Education: } \\
\hline No qualifications & $18(21)$ & $45(26)$ & $44(51)$ & $73(45)$ \\
\hline School level qualifications & $33(38)$ & $51(29)$ & $16(19)$ & $28(17)$ \\
\hline Further education & $36(41)$ & $77(45)$ & $26(30)$ & $63(38)$ \\
\hline \multicolumn{5}{|l|}{ Employment status: } \\
\hline Full time & $28(32)$ & $36(21)$ & NA & NA \\
\hline Part time & $20(23)$ & $27(16)$ & NA & NA \\
\hline Retired & $23(26)$ & $80(46)$ & NA & NA \\
\hline Not working & $16(18)$ & $30(17)$ & NA & NA \\
\hline Living with carer & NA & NA & $50(57)$ & $113(65)$ \\
\hline \multicolumn{5}{|l|}{ Relationship to recipient of care: } \\
\hline Spouse or partner & $31(36)$ & $78(45)$ & NA & NA \\
\hline Child & $42(48)$ & $71(41)$ & NA & NA \\
\hline Other & $14(16)$ & $24(14)$ & NA & NA \\
\hline
\end{tabular}

$\mathrm{NA}=$ not applicable. 
Table 3 Baseline clinical characteristics of carers and family members with dementia by randomisation group. Values are means (standard deviations) unless stated otherwise

\begin{tabular}{|c|c|c|c|c|}
\hline \multirow[b]{2}{*}{ Characteristics } & \multicolumn{2}{|c|}{ Carers } & \multicolumn{2}{|c|}{ Recipients of care } \\
\hline & $\begin{array}{l}\text { Treatment as usual group } \\
\qquad(\mathrm{n}=87)\end{array}$ & Intervention group $(n=172)$ & Treatment as usual group & Intervention group \\
\hline \multicolumn{5}{|l|}{ HADS scale: } \\
\hline Total score & $14.8(7.4)$ & $13.5(7.3)$ & NA & NA \\
\hline Anxiety & $9.3(4.3)$ & $8.1(4.4)$ & NA & NA \\
\hline Depression & $5.5(3.9)$ & $5.4(3.8)$ & NA & NA \\
\hline Quality of life-Alzheimer's disease & NA & NA & $29.9(6.9)(\mathrm{n}=87)$ & $30.2(6.9)(n=170)$ \\
\hline Health status questionnaire (mental health) & $58.2(21.7)$ & $58.3(22.4)(n=171)$ & NA & NA \\
\hline \multicolumn{5}{|l|}{ Total scores: } \\
\hline MCTS scale & $2.7(3.1)$ & $2.5(2.9)$ & NA & NA \\
\hline Zarit burden interview & $38.1(17.0)(n=84)$ & $35.3(18.4)(n=165)$ & NA & NA \\
\hline Neuropsychiatric inventory & NA & NA & $26.6(20.1)(n=86)$ & $24.0(19.0)(n=171)$ \\
\hline Clinical dementia scale & NA & NA & $1.3(0.6)(\mathrm{n}=87)$ & $1.2(0.6)(n=171)$ \\
\hline HADS anxiety case (No (\%) scoring $\geq 9$ ) & $48(55)$ & $85(49)$ & NA & NA \\
\hline $\begin{array}{l}\text { HADS depression case (No (\%) scoring } \\
\geq 9 \text { ) }\end{array}$ & $17(20)$ & $36(21)$ & NA & NA \\
\hline $\begin{array}{l}\text { MCTS (No (\%) with at least } 1 \text { item scoring } \\
\geq 2 \text { ) }\end{array}$ & $38(44)$ & $82(48)$ & NA & NA \\
\hline
\end{tabular}

HADS=hospital anxiety and depression scale; MCTS=modified conflict tactics scale; NPI=neuropsychiatric inventory. 
Table 4| Number of sessions attended by carers randomised to intervention group

No of sessions attended No (\%) of carers

None $8(5)$

$9(5)$

$211(6)$

$3 \quad 8(5)$

$47(4)$

$53(2)$

$6 \quad 1(1)$

7 1(1)

$8 \quad 125(72)$

Total

$173(100)$ 
Table 5| Primary and secondary outcomes at follow-up for carers in intervention and treatment as usual groups. Values are means (standard deviations) unless otherwise stated

\begin{tabular}{|c|c|c|c|c|c|c|}
\hline \multirow[b]{2}{*}{ Outcomes } & \multicolumn{2}{|c|}{ Treatment as usual group } & \multicolumn{2}{|c|}{ Intervention group } & \multicolumn{2}{|c|}{ Treatment effect $(95 \% \mathrm{Cl})$, P value } \\
\hline & 4 months & 8 months & 4 months & 8 months & Adjusted $^{*}$ & Adjusted $\dagger$ \\
\hline HADS total score & $14.3(7.4)(n=75)$ & $14.9(8.0)(n=71)$ & $12.4(7.4)(n=150)$ & $12.9(7.9)(n=133)$ & $\begin{array}{c}-1.46(-2.89 \text { to } \\
-0.03), 0.05(n=229)\end{array}$ & $\begin{array}{c}-1.80(-3.29 \text { to } \\
-0.31), 0.02(n=220)\end{array}$ \\
\hline $\begin{array}{l}\text { Quality of } \\
\text { life-Alzheimer's } \\
\text { disease }\end{array}$ & $29.8(5.8)(n=66)$ & $29.7(6.3)(n=61)$ & $30.7(6.5)(n=137)$ & $30.3(7.3)(n=120)$ & $\begin{array}{c}0.80(-0.45 \text { to } 2.05) \\
(n=205)\end{array}$ & $\begin{array}{c}0.59(-0.72 \text { to } 1.89) \\
(n=197)\end{array}$ \\
\hline $\begin{array}{l}\text { Health status } \\
\text { questionnaire } \\
\text { (mental health) }\end{array}$ & $58.4(18.0)(n=72)$ & $58.2(19.2)(n=66)$ & $\begin{array}{l}62.7(20.8) \\
\quad(n=144)\end{array}$ & $\begin{array}{l}58.6(22.0) \\
(n=122)\end{array}$ & $\begin{array}{c}4.55(0.92 \text { to } 8.17) \\
(n=219)\end{array}$ & $\begin{array}{c}4.09(0.34 \text { to } 7.83) \\
(n=211)\end{array}$ \\
\hline \multicolumn{7}{|l|}{ HADS: } \\
\hline Anxiety & $8.6(4.2)(n=75)$ & $8.8(4.4)(n=71)$ & $7.5(4.2)(n=150)$ & $7.6(4.4)(n=133)$ & $\begin{array}{c}-0.62(-1.43 \text { to } 0.19) \\
(n=229)\end{array}$ & $\begin{array}{c}-0.91(-1.76 \text { to }-0.07) \\
(n=220)\end{array}$ \\
\hline Depression & $5.7(4.0)(n=75)$ & $6.1(4.2)(n=71)$ & $4.9(3.9)(n=150)$ & $5.2(4.0)(n=133)$ & $\begin{array}{c}-0.88(-1.68 \text { to }-0.09) \\
(n=229)\end{array}$ & $\begin{array}{c}-0.91(-1.71 \text { to }-0.10) \\
(n=220)\end{array}$ \\
\hline $\begin{array}{l}\text { Anxiety case (No } \\
(\%) \text { scoring } \geq 9)\end{array}$ & $36(48)(n=75)$ & $33(46)(n=71)$ & $54(36)(n=150)$ & $53(40)(n=133)$ & $\begin{array}{c}0.35 \ddagger(0.11 \text { to } 1.18) \\
(n=229)\end{array}$ & $\begin{array}{l}0.30 \ddagger(0.08 \text { to } 1.05) \\
(n=220)\end{array}$ \\
\hline $\begin{array}{l}\text { Depression case } \\
\text { (No (\%) scoring } \geq 9 \text { ) }\end{array}$ & $18(24)(n=75)$ & $23(32)(n=71)$ & $25(17)(n=150)$ & $28(21)(n=133)$ & $\begin{array}{c}0.25 \ddagger(0.08 \text { to } 0.81) \\
(n=229)\end{array}$ & $\begin{array}{c}0.24 \ddagger(0.07 \text { to } 0.76) \\
(n=220)\end{array}$ \\
\hline $\begin{array}{l}\text { MCTS (No (\%) with } \\
\text { at least } 1 \text { item } \\
\text { scoring } \geq 2 \text { ) }\end{array}$ & $28(41)(n=69)$ & $23(36)(n=64)$ & $50(36)(n=139)$ & $40(33)(n=120)$ & $\begin{array}{c}0.47 \ddagger(0.18 \text { to } 1.23) \\
(n=214)\end{array}$ & $\begin{array}{l}0.48 \mp(0.18 \text { to } 1.27) \\
(n=206)\end{array}$ \\
\hline
\end{tabular}

Treatment effect estimates (differences and odds ratios) are from models taking into account repeated measurements and therapist clustering in intervention arm and that are adjusted for baseline characteristics.

HADS=hospital anxiety and depression scale, MCTS=modified conflict tactics scale.

*Adjusted for baseline score and centre.

†Adjusted also for carers' age, sex, neuropsychiatric inventory score, and Zarit burden interview.

¥Odds ratio. 


\section{Figure}

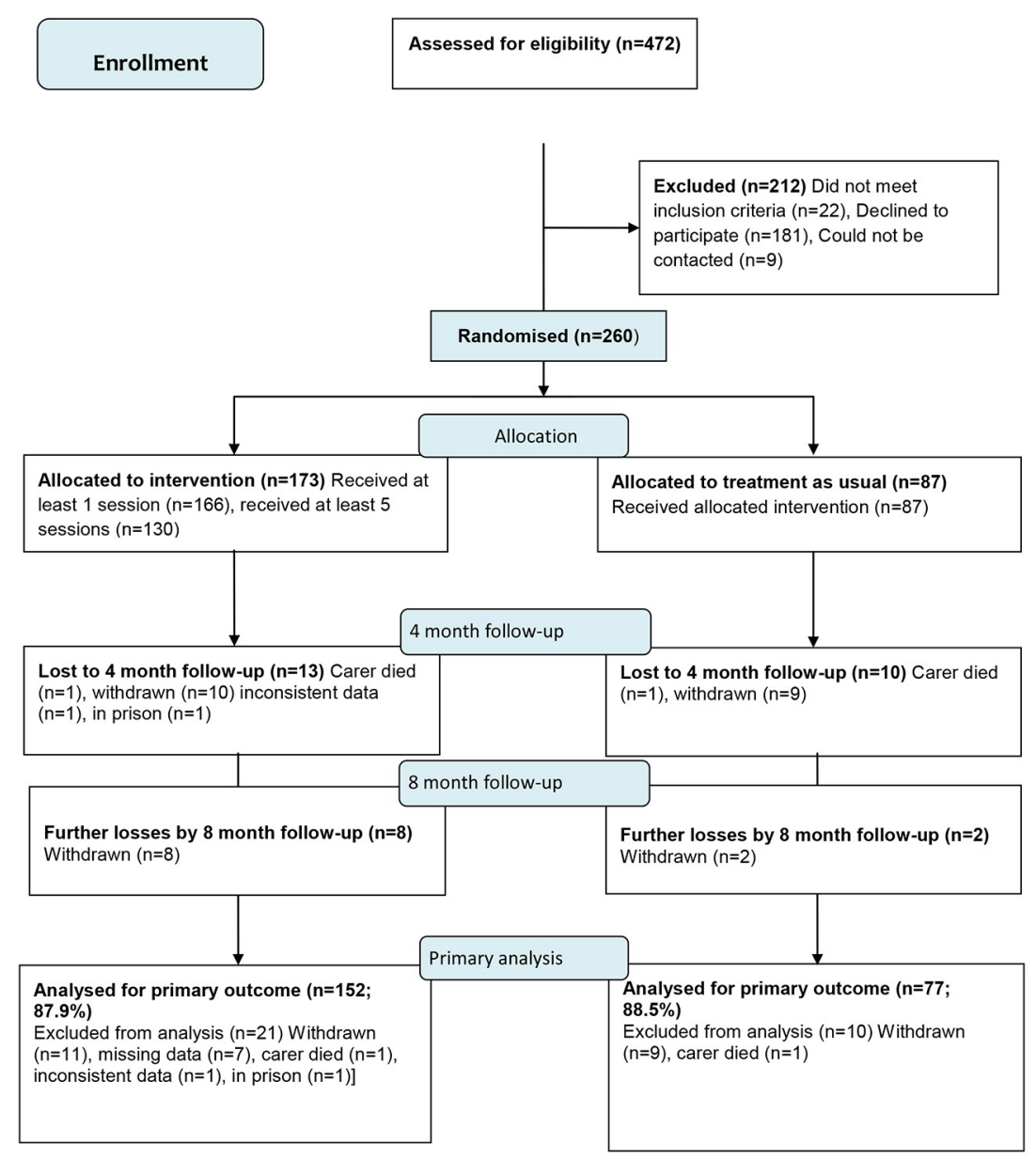

Flow of participants through study 